\title{
Amplitude Dependency Effects in the Structural Identification of Historic Masonry Buildings
}

\section{Conference Paper}

\section{Author(s):}

Martakis, Panagiotis; Reuland, Yves (i); Chatzi, Eleni (i)

Publication date:

2021-12-12

Permanent link:

https://doi.org/10.3929/ethz-b-000520763

Rights / license:

In Copyright - Non-Commercial Use Permitted

Originally published in:

Lecture Notes in Civil Engineering 200, https://doi.org/10.1007/978-3-030-91877-4_17

Funding acknowledgement:

821115 - Real-time Earthquake Risk Reduction for Europe (EC) 


\title{
Amplitude dependency effects in the structural identification of historic masonry buildings
}

\author{
Panagiotis Martakis ${ }^{1}$, Yves Reuland ${ }^{1}$ and Eleni Chatzi ${ }^{1}$ \\ ${ }^{1}$ Department of Civil, Environmental and Geomatic Engineering, ETH Zurich, CH-8057, Zur- \\ ich, Switzerland \\ \{martakis, reuland, chatzi\}@ibk.baug.ethz.ch
}

\begin{abstract}
Masonry buildings form a significant part of the central-European building stock. Despite significant efforts to standardize the seismic evaluation of such buildings, uncertainties pertaining to material properties and modeling assumptions introduce significant ambiguity. Operational modal analysis tools have been exploited to infer global structural stiffness properties, under the assumption of linear elastic behavior. However, measurements on real structures demonstrate nonlinear structural responses in the range of small strains, typically attributed to material cracking or to the soil. This work reports analysis of dynamic measurements on three real buildings at various amplitude levels, due to vibrations that are arbitrarily induced by construction works preceding planned demolition. The results show transient frequency drops that are attributed to increasing excitation amplitude, while the response remains in the commonly assumed linear elastic regime. This amplitude dependency remains poorly investigated, as vibrational data of higher amplitude for real masonry buildings are scarce. The evaluation of the impact of amplitude dependency on the, commonly assumed, linear elastic stiffness properties bears notable impact both in terms of model updating, as well as in terms of data-driven damage detection after disastrous events.
\end{abstract}

Keywords: Structural health monitoring, forced testing under demolition, output-only modal identification, amplitude dependent stiffness, existing masonry buildings

\section{Introduction}

Unreinforced masonry (URM) buildings form a key agent in terms of seismic risk evaluation in central Europe, due to their prominent share in the building stock and their high seismic vulnerability. The assessment of the seismic performance of URMs is undermined by numerous uncertainties related to material properties and the structural condition, which is altered, to an unknown extent, by non-documented structural modifications and material ageing. Despite well-established norms and advanced computational capabilities, a unified approach for the evaluation of the seismic performance of URM buildings is missing. A recent attempt on benchmarking the seismic assessment of URM buildings through a blind prediction test, exposed that even 
after adopting identical geometry and material properties, the range of the assessment results exceeds $100 \%$ of the average predictions [1]. To this end, the need of further information is evident, in order to reduce the epistemic uncertainties in the seismic assessment of URM buildings.

Ambient vibration measurements provide engineers with a non-destructive tool to derive modal properties of existing buildings, such as frequencies and mode shapes [2], [3]. In a model-updating framework, the identified modal characteristics are used to reduce the uncertainties pertaining to model parameters, such as material properties, structural integrity and foundation impedance. Although the system response during ambient excitation remains in the low-amplitude regime, where linear elastic material behavior is expected, the updated properties are proven to influence substantially the system response in the nonlinear range, by affecting the initial stiffness and consequently the plastic displacement capacity and the estimated seismic demand [4], [5]. The comparison of ambient and forced vibration experiments in real scale structures has shown the existence of reversible nonlinear behavior due to changes in excitation amplitude. Song et al. [6] investigated the inferred stiffness properties of a twostorey concrete building for varying excitation amplitude and observed an almost linear decreasing relation between the identified frequencies and the excitation amplitude. Michel et al. [7] used a shaking mass to study the amplitude-dependent modal properties and proposed a link between natural frequencies from ambient vibrations and an equivalent elastic stiffness. In previous work, the authors studied the inferred stiffness properties of a real URM building undergoing demolition and exposed the reversible reduction of masonry stiffness due to higher excitation amplitude [8]. In the same work, the impact of the elastic stiffness properties on the predicted nonlinear response, both in terms of capacity and ductility, has been demonstrated. In order to support proper assumptions regarding the elastic properties, sufficient understanding of the amplitude dependency is necessary.

The present work contains the modal identification results of three URM case studies monitored during their planed demolition in Switzerland. The acceleration data recorded during construction-site activities, prior to the first damage to structural elements, allows for extraction of signal windows showing changing levels of shaking, while ensuring that the findings are not influenced by any damage. In regions with low-to-moderate seismic hazard, such as Switzerland, measurements during demolition activities form a valuable - if not exclusive - source of vibrations to study the amplitude-dependency in the response of masonry building to dynamic loadings. Eventually, such data leads to a robust model-updating and measurement-supported seismic assessment of existing masonry structures and contributes to formulate thresholds for normal behavior of masonry structures in view of data-driven damagedetection schemes.

\section{$2 \quad$ Methodology}

For all studied buildings, a reference identification is conducted with ambient recordings, by means of the Stochastic Subspace Identification algorithm [9], in order to 
provide a baseline estimation of the modal properties. The demolition of masonry buildings involves gradual removal of elements, typically from the top to the bottom of the building, with the shovel of an excavator, as can be seen in Fig. 1 (left). Most of the non-structural elements are removed beforehand, leaving the structure at a bare state.

During demolition, buildings are subjected to hits and pulls of arbitrary direction and intensity. Such hits, which can be compared to impulse-loading, result in a rich variety of dynamic building responses. As the demolition starts from the roof, there is time window without removal of substantial mass or damage to structural components.

The Eigensystem Realization algorithm (ERA) [10] is applied on the time window of each individual impulse response and the modal properties are derived. More details on the application of ERA on impulse responses recorded during demolition can be found in [8]. Despite the infeasibility in directly measuring input excitations, the intensity metrics of the building response are used as a proxy to cluster the impulses into groups of similar amplitude. The maximum root mean square (RMS) acceleration response during each impulse is considered as intensity metric.

Characteristic impulse responses of different amplitude levels are plotted in Fig. 1 (right). The corresponding displacements are computed through double integration of the acceleration signals, in an attempt to roughly estimate the order of magnitude of the corresponding inter storey drifts. As the maximum computed displacement is lower than $0.05 \mathrm{~mm}$ and the equivalent linear range is typically considered to extend until $1 \mathrm{~mm}$ ([8], [11], [12]), it can be assumed that the structure responds in the elastic range during demolition and no damage due to excessive loading is expected. In addition, the transitory nature of the stiffness drop is verified, as there is no trend towards reduced frequencies over time.
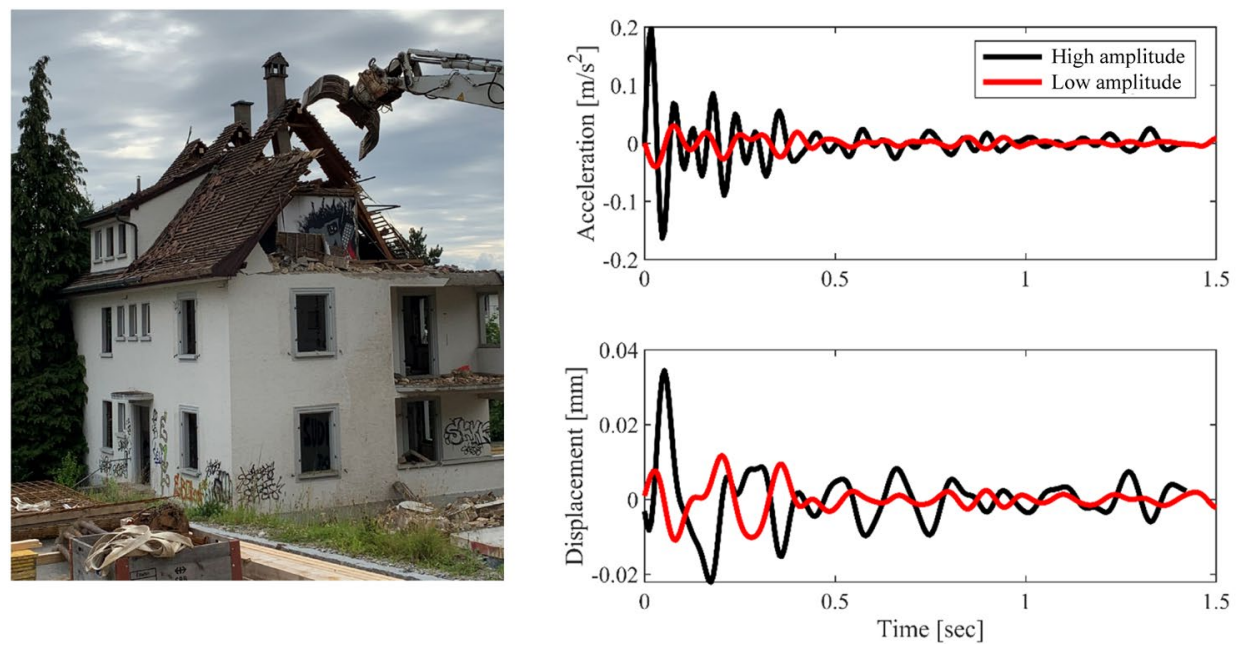

Fig. 1. Left: Photo during the demolition process from top to bottom with an excavator shovel. Right: characteristic impulse responses of various amplitude levels. 


\section{Case studies}

Three buildings have been measured during planned demolition works throughout the city of Zurich (Switzerland), in order to analyze the influence of loading amplitudes on the modal properties of existing buildings. All three buildings are masonry buildings and have been built in the first half of the $20^{\text {th }}$ century, before the introduction of seismic prescriptions into Swiss building codes. Such masonry buildings, without seismic design, form the largest part of the Swiss building inventory and contribute to the seismic risk despite the moderate hazard.

Photos of the buildings prior to the start of the demolition are provided in Fig. 2. All three buildings have a residential function and consist of two regular floors above ground level, in addition to an attic in the steeply sloped roof, and one floor, which is either partially or fully placed under the ground level. A detailed description of the building properties, following the Global Earthquake Model taxonomy [13], are reported in Table 1. All three buildings are mostly regular in plan and elevation. The dynamic response of buildings to hits with the excavator are recorded using eight triaxial MEMS-based accelerometers, which are distributed over the height of the building at strategic locations at the slab levels of the buildings, as shown in Fig. 2.
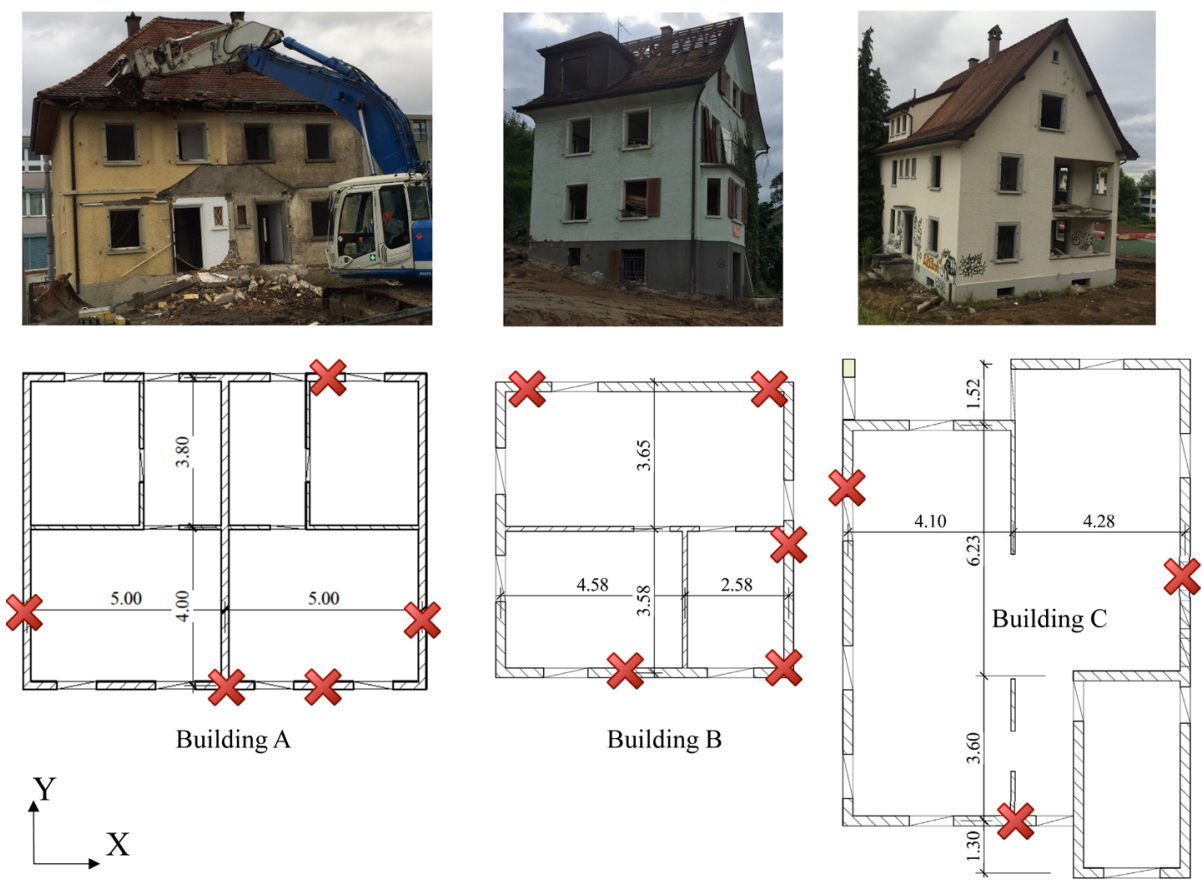

Fig. 2. Top: Photos, taken prior to the demolition, Bottom: floor plans of the three studied masonry buildings. The sensor positions are marked with red crosses. 
Table 1. Building characteristics of the studied buildings

\begin{tabular}{lccc}
\hline Property & Building A & Building B & Building C \\
\hline Year of construction & 1922 & 1927 & 1930 \\
Number of floors (above ground) & $2+$ Attic & $2+$ Attic & $2+$ Attic \\
Number of floors (below ground) & 1 & 1 (partially below & 1 (RC, partially \\
& & ground) & below ground) \\
Floor system & Flexible wooden & Flexible wooden & RC floor \\
& floors & floors & (cast-in-place) \\
Roof system & Sloped, flexible & Sloped, flexible & Sloped, flexible \\
& wooden rafters & wooden rafters & wooden rafters \\
Occupancy & Residential & Residential & Residential \\
Footprint & $78 \mathrm{~m}^{2}$ & $52 \mathrm{~m}^{2}$ & $94 \mathrm{~m}^{2}$ \\
\hline
\end{tabular}

While all three buildings share similar properties, the fundamental frequencies that are derived using the SSI algorithm from ambient vibrations in the reference phase show some variability, as can be seen in Table 2. Building A is the stiffest building, while building B shows the softest response. Fundamental frequencies above $5 \mathrm{~Hz}$ for all buildings confirm the stiffness of low-rise masonry shear buildings. Future work involves model updating of all three buildings to relate the variability in natural frequencies to structural causes, such as material parameters, foundation stiffness and layout of shear walls.

Table 2. Identified modal characteristics of the studied buildings

\begin{tabular}{lccc}
\hline Modal shape: & Building A & Building B & Building C \\
\hline Translation // X & 6.4 & 6.9 & 6.0 \\
Translation // Y & 7.4 & 5.8 & 7.3
\end{tabular}

Construction activities with heavy machinery prior to the actual demolition (removal of non-structural elements, site-preparation works etc.) generate many hits that cover a large range of amplitudes, directions and durations. Using the ERA algorithm, which is particularly suited for analysis of impulse response signals, the modal characteristics of the building response are derived for each of the hits. The identified natural frequencies related to the first bending mode in the direction with the strongest hits, normalized to the corresponding reference frequency (see Table 2), are shown in Fig. 3. As a measure of the intensity of hits, the maximum RMS of the acceleration responses of all sensors is chosen.

A clear frequency drop with increasing amplitudes can be observed for all three URM buildings. For building A, more hits have been recorded than for the two other buildings, $\mathrm{B}$ and $\mathrm{C}$, as preparatory works have been spanning over a longer time span. In addition, the higher population of hits in the low-amplitude range (below $1 \mathrm{mg}$ ) translate to a higher variability. Thus, for building A, the identified frequency is following an almost normal distribution with a mean of 0.98 and a standard deviation of 0.03 , both with respect to the reference frequency derived from ambient vibrations. 
A statistical comparison of the impulses with lower RMS with the higher-intensity impulses shows the reduction of frequency for all three buildings. However, the drop is larger for buildings $\mathrm{A}$ and $\mathrm{B}$, with a mean around $10 \%$ frequency drop, while building $\mathrm{C}$ shows less than $5 \%$ frequency drop for hits of similar intensity. Further buildings will be measured to confirm if the structural system - building $\mathrm{C}$, unlike buildings $\mathrm{A}$ and $\mathrm{B}$, has $\mathrm{RC}$ floors - is at the origin of the lesser drop of frequency with increasing amplitudes. For building A, on the other hand, the stiffness reduction is notable for hits with aRMS exceeding 2, this tendency starts at lower intensity for building $\mathrm{B}$ (at $\mathrm{a}_{\mathrm{RMS}}=1 \mathrm{mg}$ ) and building $\mathrm{C}$ (at $\mathrm{a}_{\mathrm{RMS}}=0.7 \mathrm{mg}$ ). As the acceleration may depend strongly on the location, angle, direction and severity of the hit with the shovel, as well as the distance between the hit and the closest sensor, approximate drift values will be used in future work to yield more stable results. However, the amplitude at which the stiffness starts to drop significantly and the level of drop may be building-dependent. While the intensity measure is chosen to be the maximum RMS acceleration of all channels, other measures, such as Arias intensity and peak acceleration have also been assessed, showing a lesser fit.

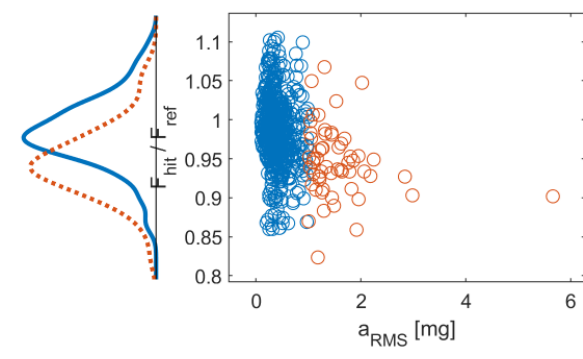

Building A

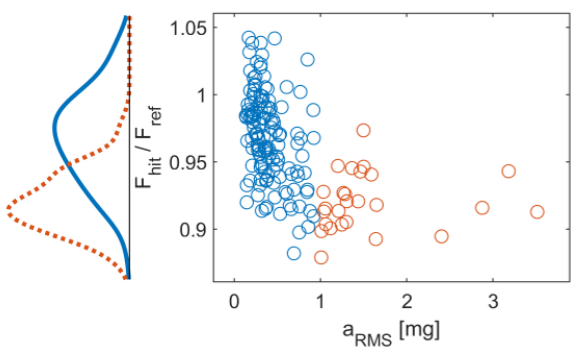

Building B

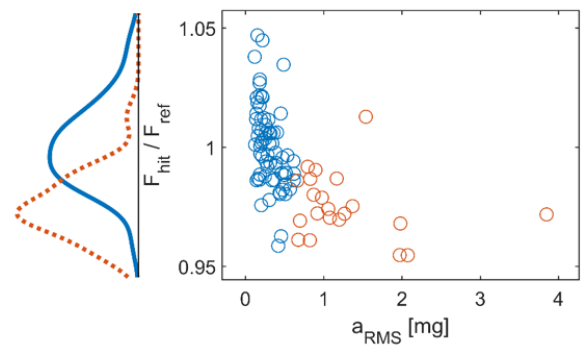

Building C

Fig. 1. Frequencies, derived with the Eigensystem-Realization method from the hits measured in the three buildings. Frequencies correspond to the mode in the direction of the strongest hits: parallel to the $\mathrm{Y}$-axis for buildings $\mathrm{A}$ and $\mathrm{B}$ and parallel to the $\mathrm{X}$-axis for building $\mathrm{C}$. Frequencies are normalized with respect to the reference identification under ambient vibrations to allow for comparisons between buildings. For better readability, axis differ between the three subplots. 


\section{Discussion of results}

Modal properties of three existing masonry buildings have been derived for impulselike excitations that are provoked by demolition activities, while the structural system of the building remained intact. The analysis of the measured building response signals in response to changing amplitudes of shaking reveals that masonry systems show transitory amplitude-dependent properties, which are not related to visible damage and which are reversible. This finding is valuable as it lays the foundation for several applications of structural-health monitoring in seismic context. First, formulating correlations between properties derived from ambient vibrations and properties under large-amplitude shaking is crucial for predictions of nonlinear behavior and the ultimate capacity with models, whose elastic properties are updated using vibration measurements. In addition, data measured in full-scale systems help in attributing the source of nonlinearity to possible sources, such as soil-structure interaction, masonry stiffness and transfer of forces between structural elements. Finally, this deeper understanding of the reversible amplitude-dependent variations of modal properties is required to avoid false positives in automated data-driven damage-detection setups.

\section{Acknowledgement}

The research described in this paper was financially supported by the Real-time Earthquake Risk Reduction for a Resilient Europe 'RISE' project, financed under the European Union's Horizon 2020 research and innovation programme, under grant agreement No. 821115, as well as the ETH Grant (ETH-11 18-1) Dynarisk - "Enabling Dynamic Earthquake Risk Assessment".

\section{References}

[1] F. Parisse et al., "Benchmarking the seismic assessment of unreinforced masonry buildings from a blind prediction test," vol. 31, no. September 2020, pp. 982-1005, 2021.

[2] P. Liu, S. Huang, M. Song, and W. Yang, "Bayesian model updating of a twin-tower masonry structure through subset simulation optimization using ambient vibration data," J. Civ. Struct. Heal. Monit., vol. 11, no. 1, pp. 129-148, 2020.

[3] H. Martín-Sanz et al., "Getting More Out of Existing Structures: Steel Bridge Strengthening via UHPFRC,” Front. Built Environ., vol. 5, no. April, pp. 1-20, 2019.

[4] J. Snoj, M. Österreicher, and M. Dolšek, "The importance of ambient and forced vibration measurements for the results of seismic performance assessment of buildings obtained by using a simplified non-linear procedure: Case study of an old masonry building," Bull. Earthq. Eng., vol. 11, no. 6, pp. 2105-2132, 2013.

[5] S. Bracchi, M. Rota, A. Penna, and G. Magenes, "Consideration of modelling uncertainties in the seismic assessment of masonry buildings by equivalent-frame approach," Bull. Earthq. Eng., vol. 13, no. 11, pp. 3423-3448, 2015. 
[6] M. Song, B. Moaveni, C. Papadimitriou, and A. Stavridis, "Accounting for amplitude of excitation in model updating through a hierarchical Bayesian approach: Application to a two-story reinforced concrete building," Mech. Syst. Signal Process., vol. 123, pp. 68-83, 2019.

[7] C. Michel, B. Zapico, P. Lestuzzi, F. J. Molina, and F. Weber, "Quantification of fundamental frequency drop for unreinforced masonry buildings from dynamic tests," Earthq. Eng. Struct. Dyn., vol. 40, no. 11, pp. 1283-1296, Sep. 2011.

[8] P. Martakis, Y. Reuland, and E. Chatzi, "Amplitude-dependent model updating of masonry buildings undergoing demolition," Smart Struct. Syst., vol. 27, no. February, pp. 157-172, 2021.

[9] P. Van Overschee and B. De Moor, "Continuous-time frequency domain subspace system identification,” Signal Processing, vol. 52, no. 2, pp. 179-194, Jul. 1996.

[10] J.-N. Juang and R. S. Pappa, "An eigensystem realization algorithm for modal parameter identification and model reduction," J. Guid. Control. Dyn., vol. 8, no. 5, pp. 620-627, Sep. 1985.

[11] Swiss Society of Engineers and Architects, SIA 269: Erhaltung von Tragwerken. Zurich, Switzerland, 2017.

[12] S. Lagomarsino and S. Cattari, "Seismic performance of historical masonry structures through pushover and nonlinear dynamic analyses," Geotech. Geol. Earthq. Eng., vol. 39, pp. 265-292, 2015.

[13] H. Crowley, S. Özcebe, R. Spence, R. Foulser-Piggott, M. Erdik, and K. Alten, "Development of a European building inventory database," 15th World Conf. Earthq. Eng., pp. 24-28, 2012. 